\title{
- High-Accuracy Finite Difference Equations for Simulation of Photonic
} Structures

\author{
G. Ronald Hadley \\ Sandia National Laboratories \\ Albuquerque, New Mexico 87185-5800 \\ (505)844/4015 \\ (505)844/8985 (FAX) \\ RECEIVEC \\ grhadle@sandia.gov \\ APR 261999 \\ ABSTRACT \\ OSTI
}

We present the derivation of sixth-order-accurate finite difference representations of the

Helmholtz Equation and use them to compute highly accurate vector eigenmode solutions. 


\section{DISCLAIMER}

This report was prepared as an account of work sponsored by an agency of the United States Government. Neither the United States Government nor any agency thereof, nor any of their employees, makes any warranty, express or implied, or assumes any legal liability or responsibility for the accuracy, completeness, or usefulness of any information, apparatus, product, or process disclosed, or represents that its use would not infringe privately owned rights. Reference berein to any specific commercial product, process, or service by trade name, trademark, manufacturer, or otherwise does not necessarily constitute or imply its endorsement, recommendation, or favoring by the United States Government or any agency thereof. The views and opinions of authors expressed herein do not necessarily state or reflect those of the United States Government or any agency thereof. 


\section{DISCLAIMER}

Portions of this document may be illegible in electronic image products. Images are produced from the best available original document. 


\title{
High-Accuracy Finite Difference Equations for Simulation of Photonic Structures
}

\author{
G. Ronald Hadley \\ Sandia National Laboratories \\ Albuquerque, New Mexico 87185-5800 \\ (505)844/4015 \\ (505)844/8985 (FAX) \\ grhadle@sandia.gov
}

SUMMARY

The success of the next generation of photonic structures will depend strongly on our ability to simulate those structures numerically prior to fabrication. Even with the recent increases in computer speeds and memory, the demands imposed by circuitry size are growing faster than our simulation capability. One partial solution to this dilemma is the introduction of new simulation algorithms that allow (to a great degree) grid-independent computing. By this is meant algorithms that are capable of providing predictions of device performance to acceptable accuracy on any reasonable grid. Codes based on such algorithms are of obvious use to experimenters who may wish to do design simulations, but who may not be experienced in the art of numerical computation. More importantly, the high accuracy of these algorithms will allow the use of coarse grids (that would otherwise result in unacceptable errors) and consequently will provide the capability to model large structures without the need for mainframe computer resources.

Progress towards the development of such algorithms as been reported for waveguide analysis ${ }^{1-3}$ and vertical-cavity laser simulation ${ }^{4}$. In all these cases, the higher accuracy order was obtained for a single spatial dimension. More recently, this concept was extended to differencing of the Helmholtz Equation on a 2-D grid, with uniform regions treated to $4^{\text {th }}$ order and dielectric interfaces to $3^{\text {rd }}$ order $^{5}$. No attempt was made to treat corners properly. In this talk I will describe the extension of this concept to allow differencing of the Helmholtz Equation on a 2-D grid to $6^{\text {th }}$ order in uniform regions and $5^{\text {th }}$ order at dielectric interfaces. In addition, the first known derivation of a finite difference equation for a dielectric corner that allows correct satisfaction of all boundary conditions will be presented. This equation is only accurate to first order, but as will be shown, results in simulations that are third-order-accurate.

In contrast to a previous approach ${ }^{3}$ that utilized a generalized Douglas scheme to increase the accuracy order of the differenced second derivative, the present method invokes the Helmholtz Equation itself to convert derivatives of high order in a single direction into mixed 
derivatives of lower order that can be differenced using a nine-point stencil. Such a stencil results in no substantial increase in matrix bandwidth and thus computer memory or runtime. At present, such high accuracies require a uniform grid with $\Delta x=\Delta y$, but it is expected that this restriction will be relaxed through future derivations with at most a two-order loss in truncation error.

The utility of these difference equations is aptly illustrated by incorporating them into an eigenmode solver and testing them on problems of varying complexity using a series of refined grids. For simple box modes involving a single dielectric interface, uncertainties in the modal index for low-order modes were typically $5 \times 10^{-6}$ for coarse grids $(6 \times 8)$ and $3 \times 10^{-12}$ for fine grids ( $96 \times 128$ ). For problems with a single corner the coarse results were similar and the fine results were slightly less accurate with uncertinties of $6 \times 10^{-10}$. These results demonstrate the power of grid-independent computing since the uncertainties obtained with the coarsest grid would likely be satisfactory to a designer in most situations. Of course, the derivations to be presented also are applicable to other types of problems, such as the simulation of reflecting structures by direct solution of the Helmholtz Equation ${ }^{5}$.

1. J. Yamauchi, J. Shibayama and H. Nakano, "Wide-angle propagating beam analysis based on the generalized Douglas scheme for variable coefficients", Opt. Lett. 20,7(1995).

2. R. Pregla, "High Order Approximation for the Difference Operators in the Method of Lines", IEEE Micro. and Guided Wave Lett. 5,53(1995).

3. G. Ronald Hadley, "Low-Truncation-Error Finite Difference Equations for Photonics Simulation I: Beam Propagation", J. Lightwave Tech. 16,134(1998).

4. G. Ronald Hadley, "Low-Truncation-Error Finite Difference Equations for Photonics Simulation II. Vertical-Cavity Surface-Emitting Lasers", J. Lightwave Tech. 16,142(1998).

5. G. Ronald Hadley, "Low-Truncation-Error Finite Difference Representations of the 2-D Helmholtz Equation”, Int. J. Electron. Commun. (AEU) 52,310(1998).

Sandia is a multiprogram laboratory operated by Sandia Corporation, a Lockheed Martin Company, for the United States Department of Energy under contract DE-AC04-94AL85000. 